\title{
LUT
}

University

Benefiting from economic crisis? Strategic orientation effects, trade-offs, and configurations with resource availability on SME performance

Beliaeva Tatiana, Shirokova Galina, Wales William, Gafforova Elena

This is a Final draft version of a publication

published by Springer US

in International Entrepreneurship and Management Journal

DOI: $10.1007 / \mathrm{s} 11365-018-0499-2$

Copyright of the original publication: ( ) Springer Science+Business Media, LLC, 2018

Please cite the publication as follows:

Beliaeva, T., Shirokova, G., Wales, W. et al. Int Entrep Manag J (2018). https://doi.org/10.1007/ s11365-018-0499-2

This is a parallel published version of an original publication.

This version can differ from the original published article. 


\section{Benefiting from Economic Crisis? Strategic Orientation Effects, Trade-offs, and Configurations with Resource Availability on SME Performance}

\section{Tatiana Beliaeva ${ }^{1}$}

St. Petersburg University, Graduate School of Management

3 Volkhovsky pereulok, St. Petersburg, 199004, Russia

Email: t.beliaeva@gsom.pu.ru

Lappeenranta University of Technology, School of Business and Management P.O. Box 20, FI-53851 Lappeenranta, Finland

Email: Tatiana.Beliaeva@student.lut.fi

\section{Galina Shirokova}

St. Petersburg University, Graduate School of Management

3 Volkhovsky pereulok, St. Petersburg, 199004, Russia

Email: shirokova@gsom.pu.ru

Far Eastern Federal University, School of Economics and Management 8 Sukhanova, Vladivostok, 690091, Russia

\section{William Wales}

University at Albany-SUNY, School of Business

1400 Washington Ave, Albany, NY 12222, USA

Email: wwales@albany.edu

\section{Elena Gafforova}

Far Eastern Federal University, School of Economics and Management 8 Sukhanova, Vladivostok, 690091, Russia

Email: gafforova.eb@dvfu.ru

\footnotetext{
${ }^{1}$ Corresponding author:

Tatiana Beliaeva, St. Petersburg University, Graduate School of Management, Russia; Lappeenranta University of Technology, School of Business and Management, Finland Email: t.beliaeva@gsom.pu.ru; Tatiana.Beliaeva@student.lut.fi Tel. +790461633 31
} 


\begin{abstract}
While there is growing interest in exploring strategic orientations, their interaction, and impact on firm performance, most research has been conducted within stable economic environments. Taking into consideration economic instability, it is timely to develop a more nuanced understanding of how economic crises may affect key strategic orientation prescriptions. In this research, we examine entrepreneurial and market orientations as means through which firms may operate within an economic crisis to seize available opportunities. Additionally, we consider how increasing financial resource availability during macroeconomic constraint may affect these relationships. Based on a rare, and robust national random sample of 612 Russian small to medium-sized enterprises (SMEs) collected during a recent period of economic crisis in 2015-2016, our results reveal a positive effect of entrepreneurial orientation and a non-significant effect of market orientation. Moreover, we demonstrate how financial resource availability in concert with firms' strategic orientations yields distinctly more, and less, productive configurations.
\end{abstract}

Keywords: Entrepreneurial orientation, market orientation, financial capital, economic crisis, small-to-medium-size enterprises, Russia

\title{
Acknowledgements
}

The authors would like to thank Scott F. Latham for his generously sharing the survey instrument with the research team. 


\title{
Benefiting from Economic Crisis? Strategic Orientation Effects, Trade-offs, and Configurations with Resource Availability on SME Performance
}

\begin{abstract}
While there is growing interest in exploring strategic orientations, their interaction, and impact on firm performance, most research has been conducted within stable economic environments. Taking into consideration economic instability, it is timely to develop a more nuanced understanding of how economic crises may affect key strategic orientation prescriptions. In this research, we examine entrepreneurial and market orientations as means through which firms may operate within an economic crisis to seize available opportunities. Additionally, we consider how increasing financial resource availability during macro-economic constraint may affect these relationships. Based on a rare, and robust national random sample of 612 Russian small to medium-sized enterprises (SMEs) collected during a recent period of economic crisis in 20152016, our results reveal a positive effect of entrepreneurial orientation and a non-significant effect of market orientation. Moreover, we demonstrate how financial resource availability in concert with firms' strategic orientations yields distinctly more, and less, productive configurations.
\end{abstract}

Keywords: Entrepreneurial orientation, market orientation, financial capital, economic crisis, small-to-medium-size enterprises, Russia

\section{Introduction}

"The Chinese use two brush strokes to write the word 'crisis.' One brush stroke stands for danger; the other for opportunity. In a crisis, be aware of the danger-but recognize the opportunity." 
In the pursuit of long-term viability and increased performance, firms must at times cope with unfavorable events and shocks that make their paths to value creation less certain. An economic crisis is a good example of a sudden environmental jolt which makes organizations reconsider their strategic approaches as they determine how best to manage the economic downturn (Kunc and Bhandari 2011; Pollard and Hotho 2006). In an attempt to respond to economic crisis, firms may adopt several distinct approaches to coherently approach competitors, customers, and make use of their resources in the pursuit of superior performance. These approaches are captured through firms' strategic orientations (Gatignon and Xuereb 1997; Venkatraman 1989).

Economic crisis presents substantial challenges and opportunities for firms attempting to weather the economic downturn and grow their businesses. Industries and markets during times of crisis experience rapid changes and increased environmental uncertainty. These dynamics inevitably shape firms' decision-making processes, including decisions regarding how to pursue entrepreneurial opportunities and address market needs. As such, firm's entrepreneurial (EO) and market (MO) orientations have the potential to play particularly important roles during such economic downturns. An entrepreneurial orientation drives firms to engage in exploratory processes and new entries (Wiklund and Shepherd 2011), whereas market orientation focuses more on exploitative possibilities derived from market gaps (Morgan and Berthon 2008).

EO and MO have been shown to provide distinct strategic paths to improved firm performance in stable economies (Hakala 2011). During times of stability, studies frequently observe a beneficial complementarity of simultaneously focusing on both $\mathrm{EO}$ and $\mathrm{MO}$, an instance where the "whole is more than the sum of its parts" (Milgrom and Roberts 1995, p. 184). Results suggest that firms combining these strategic behaviors generally show better results compared to those focusing on a single orientation alone (e.g., Atuahene-Gima and Ko 2001; Boso et al. 2012; 2013a; Deutscher et al. 2016; Ho et al. 2016; Lonial and Carter 2015).

Nonetheless, investigation of whether or not the performance consequences and complementarity of EO and MO holds during periods of economic crisis and severe market 
conditions is warranted as environmental conditions may dramatically shape their utility (Rauch et al. 2009; Rosenbusch et al. 2013). Economic crises represent exogenous shocks that elevates uncertainty, complexity, hostility, and dynamism within the external environment, and require firms to quickly make strategic decisions to adapt to new realities. Strategic orientations viewed as the principles that underlie firm's activities and behaviors to achieve superior performance (Hakala 2011), are essential for building relationships and positioning in the marketplace. Being intangible and difficult to replicate, strategic orientations offer a foundation upon which distinctive firm competencies are developed (Ho et al. 2016). Because firms have limited resources, especially during economic crisis, knowing how to best harness such resources and capabilities is an important consideration in the pursuit of competitive advantage. Firms' ability to successfully navigate economic volatility and perhaps even derive benefits from it provides a foundation for weathering the crisis and achieving longer-term prosperity. Even though attempts have been made to understand strategic orientation effects during recession (Grewal and Tansuhaj 2001; Lettice et al. 2014; Naidoo 2010; Soininen et al. 2012), prior studies have mainly focused on one orientation without considering the potential for meaningful interactions, tradeoffs, and configurations among multiple orientations during crises.

In this research, we address the call for examining and comparing the effects of two distinct strategic approaches during economic crisis (Cambra-Fierro et al. 2012; Huhtala et al. 2014) and provide new insight into how firms may position themselves to better capitalize on economic crises. As such, this research helps provide insight into several important and timely research questions. First, do complementary strategic orientations in stable environments manifest similar effects during economic crisis? Might certain behaviors enable firms to better thrive during an economic crisis? If so, do firms positively impacted by economic crises have a more entrepreneurial- or market-oriented strategic approach? Finally, does access to financial resources affect firms' efforts to yield distinctly more, and less, productive configurations? 
This study enriches our understanding of strategic behavior during economic crisis and affords several contributions to the literature. First, it provides a more nuanced perspective on how entrepreneurial and marketing strategic approaches may enable firms to navigate the challenges and capitalize on potential opportunities during economic crisis. While previous research emphasizes a need to holistically analyze firm strategy and examine multiple strategic orientations (Hakala 2011), to the best of our knowledge, this is the first study to examine how EO and MO may work separately or in tandem, and influenced by financial capital availability, to enable SMEs to effectively perform during an economic crisis. In so doing, we examine whether conventional wisdom pertaining to firms' strategic behavior holds during times of crisis.

Second, our study is unique in its sample and timing by examining Russian SMEs during a recent period of economic crisis. Thus, we avoid capturing organizational responses following a crisis and the potentially inaccurate results introduced by asking managers to accurately recollect long since past events and activities. Moreover, our data collection approach avoids a potential loss of information due to firm failures and the introduction of survival bias (Bao et al. 2011). Despite numerous challenges with collecting randomized data from SMEs in emerging markets in general, and within Russia in particular (Shirokova et al. 2013), we draw our conclusions from a nationally random sample of SMEs with data covering all regions of Russia. Taken together, the present research question, approach, and sample examine an important issue concerning firms' strategic behavior during crises, and help advance our understanding of whether and how firms may effectively perform during an economic crisis.

\section{Theoretical Background and Hypotheses}

\section{Strategic orientations and their role in enhancing firm performance}

Strategic orientations provide a basis for understanding how firms manifest business unit-level strategy (Hambrick 2003). Their importance is rooted in the ability of strategic orientations to differentiate firms based on the types of strategies they pursue. Examining fundamental 
differences in how firms strategically orient themselves enables systematic understanding and insight into how firms may successfully internally organize and externally position their organizations to harmonious meet the demands of their competitive environment.

Strategic orientations are commonly defined in terms of the strategic tendencies of a firm, which characterize its activities and behaviors, and are intended to help the organization achieve sustainable competitive advantage and improve performance (Gatignon and Xuereb 1997; Hakala 2011). Among the influential strategic orientations examined in the management literature, entrepreneurial and market orientations have both received extensive consideration. Entrepreneurial orientation encompasses firms' efforts to innovate, make bold decisions in situations involving uncertainty and elevated risk, and identify new business opportunities that they may proactively exploit faster than their competitors (Covin and Slevin 1989; Lumpkin and Dess 1996; Rauch et al. 2009). Market oriented firms seek to use market information, align their products and services to satisfy expressed and latent customer needs and also keep track of and respond to competitor's actions (Kohli and Jaworski 1990; Narver and Slater 1990).

A great deal of past research considers how strategic orientations impact firm performance (e.g., Hakala 2011; Laukkanen et al. 2013; Lonial and Carter 2015; Song and Jing 2017; Zortea-Johnston et al. 2012). Studies on the individual effects of EO and MO on firm performance have shown that they are often significantly and positively related to performance indicators, including business growth and profitability (e.g., Hult et al. 2004; Laukkanen et al. 2013; Wijesekara et al. 2016), although these relationships are neither universal across different firms nor environments (e.g., Ellis 2006; Liu et al. 2011; Slater and Narver 2000).

Moreover, researchers have investigated joint effects of strategic orientations on firm performance to examine their potential combinations and complementarities. EO and MO each represent a unique strategic approach associated with key behaviors either regarding entrepreneurship or marketing. As complementary abilities, they often create synergistic effects on performance. Following this, a group of studies have investigated interactions of EO and MO, 
and observed positive performance effects associated with their integration (e.g., Atuahene-Gima and Ko 2001; Boso et al. 2012; 2013a; 2013b; González-Benito et al. 2009).

While there is evidence of strategic orientation complementarity, studies also emphasize the importance of fit between firm's strategy and the environment. Performance outcomes from the integration of EO and MO depend on numerous contextual factors, including industry type (Zahra 2008), market conditions (Boso et al. 2013a), and competitive intensity (Boso et al. 2012). The broader macroeconomic environment also plays an important role in strategy and performance outcomes. Economic crises capture environmental conditions that may influence the efficacy of strategic orientations and modify their relationship with business performance. This signals the importance of better contextualizing strategic orientation research and findings (Meyer 2015; Miller 2011) by grasping the impact of economic crises upon the viability of key strategic orientations.

\section{Strategic orientations in the context of economic crisis}

A crisis can be defined as a period of unexpected and unfavorable external environment shifts which create intense difficulties, emerging troubles, or new threats for organizations (Vaaler and McNamara 2004). Crises have a high impact on organization's viability and imply the need to quickly make decisions to address the changing competitive landscape (Kunc and Bhandari 2011; Pearson and Clair 1998).

Firms can respond to an economic crisis in a variety of ways, such as initiating internally focused actions aimed at adapting to the shifting environmental pressures, or externally focused actions aimed at modifying their environment (Chattopadhyay et al. 2001), pursuing a defensive approach by focusing on reducing operating costs, or offensive approach by considering product or market opportunities available during the crisis (Bao et al. 2011; Tan and See 2004), adopting proactive strategies aiming to achieve market leadership, operational efficiency or both, or inconclusive reactive strategies (Alonso-Almeida et al. 2015). While retrenchment describes 
short-term actions for day-to-day survivability (Tangpong et al. 2015), a more forward-looking realignment of firms' strategies fosters longer-term viability. The strategic approaches to the crisis environment resemble firm's strategic orientations (Hakala 2011). In particular, uncovering new business opportunities and creating superior value for customers are reflected within firms' entrepreneurial and market orientations respectively (Covin and Slevin 1989; Kohli and Jaworski 1990; Narver and Slater 1990). Such strategic orientations may help firms capitalize upon an economic crisis. A review of studies on EO and MO conducted in the crisis context revealed mixed results with some studies showing a positive relationship between strategic orientations and firm performance (Cambra-Fierro et al. 2012; Lettice et al. 2014; Marino et al. 2008; Naidoo 2010), while others reporting insignificant or negative performance outcomes of strategic orientations (Grewal and Tansuhaj 2001) or its separate dimensions (Huhtala et al. 2014; Özturan et al. 2014; Soininen et al. 2012). To summarize this research, we present Table 1.

Insert Table 1 about here

While prior studies investigated EO and MO separately, the integration of these strategic orientations allows clarifying their role in business performance and creating a more holistic view on firm's strategy. Departing from research examining the impact of economic crisis on firm survival, this study examines how firms may capitalize upon, or make the most of, an economic crisis.

Entrepreneurial orientation. Economic crisis is generally viewed in terms of threats, or as creating situations in which loss is likely and firms' control over their external environment is more challenging (Bao et al. 2011). However, along with the threats, radical environmental shifts may also create potentially beneficial opportunities which can be utilized by entrepreneurial firms. Among small businesses, the exploitation of new and emerging opportunities constitutes a primary driver of their new entries and growth (Baker and Sinkula 2009). EO captures and 
characterizes firms' entrepreneurial activities which enable them to search for, create, and capitalize upon emerging business opportunities (Brouthers et al. 2015; Lumpkin and Dess 1996).

Entrepreneurial orientation is related to how emerging opportunities are perceived such that firms with lower EO perceive greater uncertainties which makes proactive, innovative, and risky competitive actions seem less desirable (Marino et al. 2008). Recent studies show that emphasizing entrepreneurial activities and introducing new products, particularly during a recession, can be an effective strategy for managing new crisis challenges (Pearce II and Michael 2006; Soininen et al. 2012). Viewing economic crisis as creating feasible opportunities, EO firms are more likely to emphasize new ideas and innovations, expanding into new product-market domains, and undertaking new ventures (Bao et al. 2011). Besides this, based on flexibility and speed of response, smaller firms adopting proactive strategies with intention to outperform competitors are more likely to respond with bold moves which may enable them to take advantage of new opportunities presented during an economic crisis (Alonso-Almeida et al. 2015). Overall, entrepreneurial orientation makes firms better prepared for the periods of crisis and tolerant of more uncertain external environments (Marino et al. 2008), allowing firms to better align their resources to exploit emerging opportunities. We posit that SMEs with higher level of EO are better able to capitalize on economic crisis while their more conservative counterparts have greater focus on immediate hardships and minimizing loss. Thus, it is hypothesized that:

H1a: The more entrepreneurial-oriented a business is, the better its ability to capitalize on an economic crisis.

Market orientation. A general consequence of economic crisis is a change in the nature of consumer demand. Crises are often characterized by higher inflation and unemployment, and as a result, consumers become more price-sensitive. They purchase less quantity or buy at a lower price, postpone their purchase decisions to the future, resort to greater information search, and 
switch brands (Grewal and Tansuhaj 2001). Despite low-demand, and high uncertainty, marketoriented firms vigorously work to collect and act on available market information. In particular, smaller firms tend to respond more quickly to market changes than their larger rivals (Lonial and Carter 2015). Market orientation, characterized with the effective usage of market information and creation of superior value for customers (Kohli and Jaworski 1990; Narver and Slater 1990), may help firms to respond to adverse economic conditions through the ongoing monitoring of customer needs and competitor strategies, and adaptation of organizational responses to the external environment. Market-oriented firms are efficient in gathering external information, understanding changes in customers' preferences and purchasing power, and rapidly making strategic decisions to satisfy those preferences.

Moreover, when market size remains stable or declines, focusing on gains in market share become more relevant (Huhtala et al. 2014). As many firms, such as small firms, lack the economies of scale necessary to compete on the basis of scale and/or price, they are more dependent on MO and customer service (Lonial and Carter 2015). Market-oriented firms may also occupy more niche markets to spread risk across different activities (Lettice et al. 2014). Thus, market-oriented firms generally outperform those with low MO, as observed within a few recent studies suggesting that the general performance impact of market orientation may increase during periods of economic crisis (Cambra-Fierro et al. 2012; Lettice et al. 2014). Therefore, we hypothesize:

H1b: The more market-oriented a business is, the better its ability to capitalize on an economic crisis.

\section{The role of financial capital during economic crisis}

Financial capital represents the most essential and flexible organizational resource during a crisis. It can be relatively easily transformed into other resource forms and guards against resource constraints in key operational areas. We define financial capital as the extent to which 
capital resources are available and accessible to the firm to fund business operations (Cooper et al. 1994; Wiklund and Shepherd 2005). Access to financial capital is particularly important for SMEs, which often face a liability of smallness arising from limited resources, making them more vulnerable to environmental shifts (Aldrich and Auster 1986; Kale and Arditi 1998). Compared to large organizations, smaller firms experience greater difficulties in raising capital and recruiting qualified labor, and are typically in worse negotiating positions due less market presence and market power (Strotmann 2007). Liabilities of smallness are even more pronounced during the crisis period, when the economy experiences a slowdown of economic growth and environmental munificence declines.

Yet, having access to financial resources enhances the pursuit of strategic objectives (Bai et al. 2006; Wiklund and Shepherd 2005). It has been noted that both EO and MO, while being valuable firm strategic orientations, are each costly and resource-intensive (Covin and Slevin 1991; Kumar et al. 2011; Morgan et al. 2015; Wiklund and Shepherd 2011). When financial resources are scarce during an economic crisis, firms with capital may empower their strategic orientations. Thus, access to financial capital is expected to interact with EO and MO in explaining firm's ability to better capitalize on opportunities during an economic crisis.

The interaction of EO and financial capital availability. Entrepreneurial firms have a great need for financial resources. Financial capital allows EO firms to experiment with new projects that might otherwise be prohibited (Bradley et al. 2011; Cooper et al. 1994; Wiklund and Shepherd 2005). Moreover, available financial capital allows such exploration of new opportunities without taking resources away from existing product-markets (Boso et al. 2012). When resources become cheaper in factor markets during economic crises, entrepreneurial arbitrage opportunities to acquire resources to foster growth and expansion become available to those which still have access to the financial capital to take advantage of the potentially great deals. Thus, we draw upon theory of arbitrage capital (Acharya et al. 2013) to explain this potential interaction. Taking advantage of more EO opportunities enables the SME to grow and 
expand more rapidly, and be better poised for yet faster growth when the economy begins to recover. Moreover, with greater EO, firms may discover new ways to combine their resource bases and bricolage or effectually create new combinations with newly accessible, price reduced assets in the marketplace. Greater financial capital also protects firms from the uncertain outcomes of new projects, thus fostering risk-taking and market leadership. In this vein, it can be assumed that greater access to financial resources enhances firms' EO, and positively moderates its relationship with performance capitalization during economic crisis. Formally:

H2a: The relationship between EO and firms' ability to capitalize on economic crises is positively moderated by financial capital availability, such that performance capitalization increases with EO at a faster rate for firms with greater access to financial capital.

The interaction of $M O$ and financial capital availability. Market-oriented activities, including customer service, market analysis, promotions, and collaboration with suppliers and other stakeholders, similarly demand financial resources. Greater access to financial capital may facilitate the implementation of market-oriented strategy during the crisis times (Kohli and Jaworski 1990). Moreover, firms with greater financial resources are in a comparatively stronger position to offer superior value and services to customers than their resource-constraint rivals, as they are in a position to invest more firm effort into getting the most out of accessible markets (Kaleka 2002). Financial resources provide firms with the ability to conduct more profound market analyses, better monitor changing customer needs, and systematically measure customer satisfaction. Thus, it can be assumed that the benefits of MO during economic crisis may be facilitated when firms have greater access to financial capital. We hypothesize:

H2b: The relationship between MO and firms' ability to capitalize on economic crises is positively moderated by financial capital availability, such that performance capitalization increases with $\mathrm{MO}$ at a faster rate for firms with greater access to financial capital. 
An integrative model of $E O, M O$, and financial capital availability

How firms' strategic orientations interact, reinforcing or competing with one another, remains an important question (Boso et al. 2012; 2013a; Deutscher et al. 2016; Li et al. 2010). Research implies that various strategic orientations capture different mechanisms for sustaining competitive advantage and have the potential to support each other, create additional value, and enhance business performance. Fueled by financial capital availability, the resource competition between EO and MO is lessened within the context of economic crises, and firms may seek to pursue and benefit from both strategic orientations and approaches to competition.

Studies on the relationship between EO and MO are generally consistent in that integration of these strategic orientations frequently enables SMEs to perform better (Boso et al. 2013b; Lonial and Carter 2015). Moreover, during periods of economic crisis, firms that balance EO and MO may capitalize on emerging market opportunities by better identifying customer needs. Greater levels of EO are required to take advantage of new business opportunities, but along with this entrepreneurial behavior entails uncertainties and risks especially in the context of economic crisis. While strong focus on MO is important for quickly adapting to changing customer needs, left unchecked it may also decrease firms' emphasis on innovativeness and entrepreneurial initiatives. Thus, the adaptiveness of MO to current markets can be complemented by the explorative nature of EO (Boso et al. 2013b).

Contextually, access to resources provides firms with the slack to experiment with strategies that are unlikely to be approved in more severe and uncertain environments. Given the resource intensity of entrepreneurial and marketing activities, a recent study has shown that firms benefit more from combining $\mathrm{EO}$ and $\mathrm{MO}$ when they have strong financial resources to implement and maintain these strategic orientations (Boso et al. 2012). Financial slack broadens strategic options and enables firms to choose those which provide greater chances to success, rather than to be restricted by their implementation costs (Voss et al. 2008). In contrast, firms pursuing multiple strategic orientations with lesser access to financial capital may take shortcuts 
which undermine the quality of their multiple strategic orientations (Boso et al. 2012). Building on past research, we assert that in times of crisis firms will perform the best when they exhibit strong EO, MO, and have adequate access to financial capital. Thus, we hypothesize:

H3: Firms' ability to capitalize on economic crises is highest among firms with high levels of EO and MO, and greater access to financial capital, and lowest among firms with low levels of EO and MO, and little access to financial capital.

An overview of the research model investigated is presented in Figure 1.

Insert Figure 1 about here

\section{Method}

\section{Country context and sampling}

For this study, we surveyed Russian SMEs during a period of recent economic crisis. Data were collected from September 2015 to February 2016. Sampled firms are all privately owned, span different industries and of note, all country regions are represented. In late 2014, the global economy experienced a more than $60 \%$ drop in oil prices, the principal source of income for the Russian state budget. The recent economic crisis in Russia is characterized by a co-movement of many macroeconomic indicators: the economic growth rate in Russia slowed down by $2.8 \%$ in 2015 as measured by gross domestic product (GDP) with the biggest decline in manufacturing, trade, construction and service industries, the national currency lost over $50 \%$ of its value and inflation reached nearly $13 \%$, leading to a significant decline in investments and household incomes, and rise in bankruptcies among Russian SMEs (Federal State Statistics Service 2017). The sharp declining in the price of ruble negatively impacts import-dependent industries, increasing their production costs. Demand reduction and higher price sensitivity of consumers decrease the sales volume of many Russian firms and particularly hit retail sector as households, reducing their expenditures, postpone large purchases until better times. The increased price of foreign financing caused by currency fluctuation and domestic interest rates as a result of 
monetary policy held by Central Bank of Russia, created difficulties for Russian firms in funding their current business operations and investing in new projects (Mau and Ulyukaev 2015). The economic downturn occurs simultaneously with the strengthening of economic sanctions against Russia, further decreasing business confidence among companies.

To develop our sample of Russian firms we generated a list of random private Russian companies using the Main State Registration Number (OGRN), which is entered in the Unified State Register of Legal Entities while a company is being registered at the tax authorities. ${ }^{1}$ The list of randomly generated OGRN codes was then downloaded into the information-analytical SPARK Interfax database ${ }^{2}$ to check the validity of the generated codes, download firm information and key financials, and apply a filter to meet the selection criteria of the study. According to the company selection criteria applied in the study, the large companies (with more than 500 employees and classified as large by SPARK database), micro enterprises (with fewer than three employees), governmental organizations, companies operating in the agricultural sector supported by the government, and companies with the "liquidated" status were excluded from the list. We selected firms having at least three full-time employees because of the focus of the study on organizational strategic orientations, and, therefore, as a phenomenon is less clear in the context of individual entrepreneurs and very micro enterprises. We included firms with fewer than 500 employees based on the sales revenue used to determine SMEs (Shirokova et al. 2013). As the debate in the Chamber of Commerce of the Russian Federation demonstrates, this approach is appropriate in the Russian national context (Chamber of Commerce and Industry of the Russian Federation, n.d.). All selected firms were classified as SMEs by the SPARK database. In total, 10,359 SMEs for the survey were selected.

\footnotetext{
${ }^{1}$ The Main State Registration Number of a Russian company is a 13-digit combination which consists of the following parts: the status of the state registration number, year of registration, constituent entity of Russian Federation, tax inspection code, record number, and control figure.

${ }^{2}$ SPARK Interfax database includes the information about all legal entities and individual entrepreneurs registered in Russia and uses constantly updated data from official government databases. The database allows finding information on any registered company, using a registration number, including OGRN, and provides detailed information about the company, such as its registration information, financial statements, description of activities, information on liabilities, decisions of arbitration courts, and other company information. http://www.sparkinterfax.ru/promo/en/\#_top.
} 
The survey was conducted using a standardized questionnaire administered through the combination of an online survey instrument and telephone interviews. To avoid any potential difficulties in answering to the questions, the questionnaire was pretested on a small sample (20 SMEs). We made a validation of the selected firms by calling their telephone numbers. The number of target companies which were invited to participate in the survey was estimated as 2,583 firms ${ }^{3}$. Then, we distributed the standardized questionnaire to firms' founders and/or CEOs, given their responsibility for strategic management within the organization (Deutscher et al. 2016). The interviewers were able to monitor the respondents' progress in filling in the questionnaire and, if necessary, to send a reminder or provide assistance. Overall, we obtained 656 questionnaires with an effective response rate of $25.4 \%(656 / 2,583)$. After cleaning the data for missing values, the final dataset of Russian SMEs used in all further analyses was equal to 612 usable observations.

The majority of sampled firms (88.07\%) are small firms with less than 100 employees. On average, firms are 13.6 years old. Most of them belong to the wholesale $(21.90 \%)$, services $(21.73 \%)$, and retail trade $(17.48 \%)$ industries, followed by manufacturing $(16.83 \%)$ and construction industries (11.60\%). The sampled firms are spread across the different country regions with the majority operating in Central (27.78\%), Volga (19.28\%), and Siberian (18.46\%) Federal Districts, followed by the Northwestern (11.93\%) and Ural (11.76\%) Federal Districts. Industries and federal districts participating in this study are presented in Table 2.

Insert Table 2 about here

\section{Measurement}

Table 3 describes the specific items used for construct measurement based upon established scales within the management literature and their respective factor loadings.

\footnotetext{
${ }^{3}$ This figure indicates the number of validated (e.g., corresponding to the selection criteria) firms which were called by phone to participate in the survey. This figure includes all firms invited to participate via phone including those which accepted as well as those that declined. The approached firms called by phone were selected using equipment that enables the random selection of phone numbers from the total sampling frame $(10,359)$.
} 
Insert Table 3 about here

Dependent variable. To capture firm's ability to capitalize on economic crises, we utilized the respondents' assessment of the impact of economic crisis on their firm performance on a seven-point Likert scale with the anchors 1 - very negatively impacted, to 7 - very positively impacted (Latham 2005). The respondents assessed the extent to which the economic crisis positively or negatively impacted their organization across key performance metrics: sales revenue, profitability, pricing, and average deal size. Subjective performance measures are widely used in this research area (Deutscher et al. 2016; Rauch et al. 2009; Wiklund and Shepherd 2005) and are particularly applicable to the studies of small private firms which are more reluctant to disclosure confidential financial data (Baker and Sinkula 2009; Lonial and Carter 2015), and to the studies in economic crisis context (Grewal and Tansuhaj 2001; Naidoo 2010; Soininen et al. 2012) in which financial condition of firms may not be adequately indicated by objective measures. Besides this, as objective performance indicators differ across industries, subjective measures are more appropriate in cross-industry studies (Deutscher et al. 2016). Prior research has found strong empirical support of the high correlations among objective and subjective measures (Ling and Kellermanns 2010) which allows considering the latter as a reliable indicator of firm performance.

Independent variables. The level of firm's entrepreneurial orientation was measured with the seven-point Likert scale adapted from Covin and Slevin (1989) and Lumpkin and Dess (2001). Given that we seek to assess the performance outcomes of EO as an overall strategic orientation, a unidimensional approach to EO conceptualization was applied in line with the predominant manner in which EO has been examined in past research (Wales et al. 2013). The nine-item scale captures the dimensions of innovativeness, proactiveness, and risk-taking.

Market orientation was measured with a fifteen-item seven-point Likert scale adapted from Narver and Slater (1990) (MKTOR scale) which captures the dimensions of customer 
orientation, competitor orientation, and inter-functional coordination. This scale has been shown to be a valid means of assessing firms' market orientation (Cano et al. 2004).

Financial capital availability was measured with a four-item seven-point Likert scale adapted from Story et al. (2015). The measure assessed managers' satisfaction levels with the extent to which their firms have access to financial capital to support their business operations, the availability of financial resources at the discretion of managers, and the ability to obtain financial resources at short notice to fund business initiatives.

Control variables. To provide additional assurances of study findings, a number of control variables were included within the analysis. The level of strategic orientations and performance impact of economic crisis might also be contingent on firm characteristics, including firm size, firm age, industry type, and past performance, as well as the regional environment, as certain regions may be differentially affected during the economic downturn.

Firm age was estimated by the number of years since a firm's foundation. Firm size was measured as a firm's overall number of full-time employees. Firm's age and size were both natural $\log$ transformed to address the assumption of distribution normality. To control for industry-specific differences, eight dummy variables were created based on the Standard Industrial Classification (SIC) and tapping whether a firm operated in one of the following industries: exploration and mining of minerals; construction; manufacturing; transportation and logistics, communications, electricity, gas and sanitary services; wholesale trade; retail trade; services; or other. For additional assurances, firm's past performance was assessed by an objective financial indicator of sales revenue in the pre-crisis period of 2014, obtained from the SPARK Interfax database. A natural logarithm transformation of the measure was employed.

To control for differences between the country regions, we utilized an index of regional development, obtained from the "Quality index of conditions for small and medium business in 2013-2014. Regional disproportions" (SME Bank 2015). This measure assesses the level of development of the regional environment (coded as 1 - insufficient, 2 - sufficient, 3 - good) and 
includes five components: access to resources needed for doing business; demand and competitive environment; the level of business support from the regional authorities; macroeconomic risks; and risks related to the crime, excessive administrative barriers, and corruption. The items were summed to create an overall index of the regional development. Additionally, we controlled for the dynamics of Gross Regional Product (GRP) in 2015 as a percentage of the previous year, obtained from the Federal State Statistics Service.

\section{Assessing common method variance}

For additional robustness, we examined the potential threat of common method bias to our study findings using two established tests. First, Harman's one-factor test was applied. Conducting a principal component factor analysis across study variables yielded six factors with eigenvalues greater than one. The variance explained by the first factor accounted for $31.84 \%$ of the total variance and no factor accounted for the majority of variance thus indicating that the data do not appreciably suffer from common method bias (Podsakoff and Organ 1986). Secondly, a confirmatory factor analysis (CFA) was applied to estimate three competing measurement models (Cote and Buckley, 1987): (1) loading of all the items on a single latent factor $\left(\chi^{2} / d f=\right.$ 14.67; GFI $=0.64 ; \mathrm{TLI}=0.51 ; \mathrm{CFI}=0.57$;MSEA $=0.15) ;(2)$ loading of each item on its respective latent factor $\left(\chi^{2} / d f=2.00 ; \mathrm{GFI}=0.94 ; \mathrm{TLI}=0.96 ; \mathrm{CFI}=0.97 ; \mathrm{RMSEA}=0.04\right)$; and (3) loading the items on their latent variables and an additional common latent factor $\left(\chi^{2} / d f=\right.$ 2.06; $\mathrm{GFI}=0.94 ; \mathrm{TLI}=0.96 ; \mathrm{CFI}=0.97 ; \mathrm{RMSEA}=0.04)$. We observe that adding a common method factor to model 1 and 3 does not substantially improve model fit compared to model 2, thus common method bias is not evidenced. In addition, the empirical analysis includes a number of interaction terms and complex relationships, which are unlikely to be perceived by respondents (Chang et al. 2010). 


\section{Results}

\section{Measurement model fitness}

To validate the measurement model for the latent variables examined, a confirmatory factor analysis using maximum likelihood estimation was performed. Moreover, we assessed the unidimensionality, reliability, and validity of all study measures to ensure their appropriateness for our investigation (Fornell and Larcker 1981; Gerbing and Anderson 1988).

As noted earlier, prior to data collection, a pretest of the questionnaire was conducted on a small sample (20 SMEs) to assess the face and content validity of the instruments and minimize potential question ambiguity and problems with responding. Following our data collection, a confirmatory factor analysis which specifies a measurement model defining the relationship between each latent variable and its constituent items, was conducted to demonstrate construct integrity. CFA helps to identify problematic items in the constructs, and, based on the factor loadings and modification indices several items were removed from the scales, resulting in improvement of the overall model fit. Since entrepreneurial and market orientations are the second-order scales, they were tested separately from first-order factors. All measurement models exhibit a good fit to the data (entrepreneurial orientation/ market orientation/ financial capital availability and performance impact of economic crisis: $\chi^{2} / d f=1.06 / 1.89 / 2.16$; GFI $=$ $0.99 / 0.98 / 0.99 ; \mathrm{TLI}=0.99 / 0.99 / 0.99 ; \mathrm{CFI}=1.00 / 0.99 / 0.99 ; \mathrm{RMSEA}=0.01 / 0.04 /$ 0.04), indicating that all items load on singular underlying latent variables respectively. Table 3 contains the final list of items, the standardized factor loadings, and the results of key reliability and validity tests.

Cronbach alpha statistics for all the constructs exceed 0.70 threshold (Nunnally 1978), establishing the reliability of the instruments. Specifically, the coefficient alphas for entrepreneurial orientation, market orientation, financial capital availability, and performance impact of economic crisis are $0.88,0.87,0.91$, and 0.91 , respectively. 
All items of multi-item scales significantly $(p<0.001)$ loaded on their corresponding latent constructs with the minimum factor loading being 0.64 , which is well above 0.50 level and confirms adequate convergent validity of the measures. The Composite Reliability (CR) indices of all constructs in the obtained sample are above the stipulated cut-off point of 0.70 .

Discriminant validity of study measures was assessed in three different ways. Firstly, the correlation coefficients of the study constructs were examined (Table 4). The results of the bootstrapping analysis (1000 resamples) of the correlation coefficients between the composite constructs demonstrate that none are included one in the 95-percent confidence interval. Secondly, the Average Variance Extracted (AVE) statistics for all latent variables was compared with the shared variance between them (Fornell and Larcker 1981). The shared variance for the scales ranged from a low of $0.78 \%$ to a high of $12.6 \%$, with the average variance extracted ranging between $63 \%$ and $74 \%$, indicating that for each construct, AVE was much higher than its highest shared variance with other constructs. Thirdly, the discriminant validity was tested by calculating the difference between a constrained model in which the correlation between each of the two latent variables was fixed to one, and an unconstrained model in which the correlation was freely estimated. The results of testing a chi-square difference between the two models indicated that all construct pairings exhibit significant difference at $p<0.001$. Taken together, these findings affirm the discriminant validity of the study constructs.

Finally, the resulting values of latent variables were calculated as an average score on all the items. To measure the strategic orientations, the item scores were averaged for each dimension of a particular orientation which were then combined (averaged) to evidence a given orientation.

Table 4 contains descriptive statistics of the sampled firms and the correlation matrix for all variables used in the study. The largest correlation coefficient between the studied variables is 0.56 (between firm size and past performance), implying only $31 \%$ of the shared variance. This addresses concerns regarding the possibility of multicollinearity in the study. 


\section{Hypothesis testing}

The empirical analysis was performed using a hierarchical ordinary least squares (OLS) regression analysis approach with moderator analysis. We employed heteroskedasticity-robust standard errors adjusted for the eight federal district clusters to control for potential heteroskedasticity in the OLS estimation and possible correlated errors across observations.

The test for multicollinearity in the regression model with main effects demonstrates that all variance inflation factor (VIF) indices are within an acceptable range with an average VIF of 1.33 and maximum of 1.93 , assuaging possible concerns of multicollinearity and implying that the model with all variables included can be estimated.

To analyze the hypothesized relationships, the following equation was estimated ${ }^{4}$ : Performance impact of economic crisis $=[$ Controls $]+[\mathrm{EO}+\mathrm{MO}+\mathrm{FC}]+[\mathrm{EO} \times \mathrm{FC}+$ $\mathrm{MO} \times \mathrm{FC}+\mathrm{EO} \times \mathrm{MO}]+[\mathrm{EO} \times \mathrm{MO} \times \mathrm{FC}]+\varepsilon$,

The hypothesis testing was performed in several steps: first, all control variables were included (Model 1), then the main effects of strategic orientations and financial capital availability were added (Model 2), followed by the two-way interaction effects (Model 3) and finally, the three-way interaction effect (Model 4). To facilitate the interpretation of results and avoid multicollinearity problem in more complex models with interaction effects, prior to calculating the interaction terms we mean centered the variables (Aiken and West 1991). The restricted models (Models 1-3) were compared with the unrestricted model (Model 4) by observing variations in $\mathrm{R}^{2}$ change. The results are presented in Table 5.

Insert Table 5 about here

\footnotetext{
${ }^{4} \mathrm{EO}=$ entrepreneurial orientation; $\mathrm{MO}=$ market orientation; $\mathrm{FC}=$ financial capital availability; $\varepsilon=$ error term.
} 
Hypotheses 1a and 1b, regarding the positive direct effects of individual strategic orientations on firms' performance capitalization during an economic crisis, were tested in Model 2. We find that the more entrepreneurially oriented a firm is, the better it is able to capitalize on unfavorable economic conditions compared to other firms $(b=0.13, p<0.05)$. The significant and positive effect of EO remained in Models 3 and $4(b=0.14, p<0.05 ; b=0.14, p$ $<0.05)$. However, intriguingly, we do not find any significant direct impact of market orientation on the dependent variable. Therefore, the findings partly support the first research hypothesis as we find support for H1a, showing that firms may primarily benefit from emphasizing entrepreneurial elements of their strategy-making during a period of economic crisis. Additionally, availability of financial capital allows firms to better capitalize on an economic crisis $(b=0.17, p<0.001)$. As for the control variables, firm age is negatively $(b=-0.21, p<$ $0.10)$, and firm size $(b=0.12, p<0.10)$ and GRP dynamics $(b=0.04, p<0.10)$ are positively related to performance capitalization during times of crisis (Model 1).

Hypotheses $2 \mathrm{a}$ and $2 \mathrm{~b}$ examining potential contingency relationships between strategic orientations and financial capital availability were tested in Model 3. The coefficients of the interaction terms are found to be insignificant, therefore the second study hypothesis does not receive statistical support. Yet, the relationship between strategic orientations and availability of financial resources might be more complex and better explained by a configurational rather than contingency-based theoretic approach. Interestingly, the interaction between EO and MO revealed a negative effect on firm's ability to capitalize on economic crisis $(b=-0.11, p<0.05)$, suggesting that performance effect of EO is weaker when levels of MO are high.

Hypothesis 3 regarding a potential interaction of $\mathrm{EO}, \mathrm{MO}$, and financial capital availability is tested in Model 4. A three-way interaction effect is observed to be negative and significant $(b=-0.05, p<0.05)$. Thus, an integrative approach provides a more complete picture of firm strategic behavior and better explains variance in performance capitalization during an economic crisis compared to either a main-effects or contingency model. 
To understand the nature of the relationship between entrepreneurial orientation, market orientation, and financial capital availability, the interactive effects using sub-group analysis were plotted (Aiken and West 1991). The level of EO was plotted on the performance impact of economic crisis for low (one standard deviation below the mean) and high (one standard deviation above the mean) values of MO and financial capital availability, thereby depicting four different configurations of strategic approaches and resource availability (Figure 2).

Insert Figure 2 about here

As Figure 2 indicates, a more positive performance impact of economic crisis is achieved when a firm develops a high level of EO, has financial capital to support its business operations, and deemphasizes its MO. In contrast, firm performance is more negatively impacted by economic crisis when a firm has low levels of both strategic orientations, and financial capital availability. Thus, the findings partially support hypothesis 3. Intriguingly, the simultaneous development of both EO and MO does not enhance firm's ability to capitalize on an economic crisis. Instead, the marginal benefit of EO decreases as the level of MO increases, suggesting a substitute rather than complementary interaction between the strategic orientations (Voss et al. 2010). A substitute interaction suggests that simultaneous investment in both strategic orientations produces diminishing or even negative returns, and greater performance benefits during economic crisis are achieved when a firm adopts a high level of entrepreneurial (as opposed to market) orientation.

Additionally, the differences in the regression slopes in four configurations were tested. Following a method adapted from Dawson and Richter (2006), six pairs of the four slopes were compared (Table 6).

Insert Table 6 about here 
The results show significant differences $(p<0.05)$ between the slopes 1 (high MO, high FC) and 3 (low MO, high FC), and the slopes 1 and 4 (low MO, low FC), and marginal differences $(p<0.10)$ between the slopes 2 and 3, and the slopes 3 and 4 , further supporting that entrepreneurial orientation most strongly contributes to firms' performance capitalization during the economic crisis when market orientation is low and financial capital availability is high.

\section{Robustness evaluations}

We conducted several robustness checks to further enhance the confidence in our study findings. First, we ran the regression models in which all latent variables were operationalized as factor scores. To produce consistent estimators for all parameters, regression factor scores for the explanatory latent variables along with a Bartlett score for the latent response variable were used (Skrondal and Laake 2001). The same steps in the hierarchical regression analysis were followed. Results are consistent evidencing a hypothesized positive effect of EO $(b=0.14, p<$ 0.05 ) on firm's ability to capitalize during an economic crisis, and a significant negative threeway interaction effect of EO, MO, and financial capital availability $(b=-0.07, p<0.05)$. Second, the model was estimated without control variables to test for the presence of Type I error due to spurious relationships between the main and control variables. The model results did not reveal any changes in terms of coefficient signs or significance levels for our main (EO: $b=0.13, p<$ 0.05 ) or configurational effects (EO, MO, and FC: $b=-0.05, p<0.05$ ), which provides additional support for the evidenced relationships. Third, given the critical observed role of EO, the models were checked for applicability across both innovative and non-innovative firms (innovativeness level $\geq 5(n=181)$, and $<5(n=431)$, respectively). In both subsamples, entrepreneurially-oriented firms demonstrated greater ability to "cash in" during economic crisis, an effect which held when EO was also augmented with low MO. Thus, going beyond much of past research, this additional analysis suggests that the major conclusions from our research model generally hold irrespective of an organization's level of innovativeness. As a final 
robustness check we estimated the model with an objective financial indicator of firm's total assets in 2015 (natural logarithm taken) as a proxy for financial capital available to the firm during economic crisis. Information on total assets was available in SPARK Interfax database for 580 firms from our sample. The objective assessment of firm's financial capital is significantly correlated with the subjective one $(r=0.11, p<0.05)$, and the estimated model is similarly in line with the observed positive EO effect $(b=0.14, p<0.05)$ which is further strengthened when the level of MO is low, establishing robustness of the results across different operationalizations of the variable.

\section{Discussion}

To date, our knowledge of strategic orientations and their effects on performance overwhelmingly stem from studies conducted within stable economic environments. Nonetheless, might economic crises alter the nature of established strategic orientation relationships in new and surprising ways? This research suggests that the answer to that question is a resounding yes. Our results suggest that firms are best able to capitalize upon the opportunities present during an economic crisis through manifesting a strong EO. Surprisingly, in our crisis context, MO is not found to manifest similar benefits. This suggests that studying customers and competitors provides less useful insights when an economic crisis is occurring than when the environment is more stable. These findings provide insight into the value afforded by entrepreneurial and market orientations during an economic crisis.

Several meaningful implications stem from this research. To begin, our conclusions are based upon an unprecedented national random sample of 612 SMEs spanning all federal districts in Russia. We first consider our findings pertaining to the value of EO during an economic crisis from a resource-based lens (Barney 1991). Firms that have access to resources, particularly financial resources, during an economic crisis are presented with a period of reduced consumer demand, but also a period in which external resource costs plummet enabling EO firms to 
acquire, exploit temporary arbitrage opportunities, and position themselves to emerge from the crisis with stronger resources bases. Thus, our results appear consistent with theories of arbitrage capital (Acharya et al. 2013). EO firms take the risks, act proactively, and identify innovative means of developing forward-looking competitive advantages during economic crisis.

However, firms with a market orientation are not as positively impacted during an economic crisis. Past results concerning the value of MO during economic crisis have been mixed with some studies suggesting a beneficial effect (Lettice et al. 2014), and others suggesting a detrimental effect (Grewal and Tansuhaj 2001). When EO is considered alongside MO, our results provide additional insight into this tension suggesting that firms perform best when emphasizing EO as opposed to MO during economic crisis. While entrepreneurial firms may observe many opportunities during a crisis, market-focused organizations that intensely consider what their competitors are doing or how best to address customer needs appear to experience limited gains. To speculate, during periods of reduced customer demand, it's likely that the information provided by a marketing orientation may point the firm towards less profitable short-term opportunities to adapt to changes in recessionary market demands when firms are better served focusing on their resource bases, potential entrepreneurially-oriented arbitrage opportunities, and building the organization for long-term gains. EO behaviors may take years to pay off (Zahra and Covin 1995). In this vein, an economic recession is arguably among the best times to exhibit an EO as by definition the short-term does not present the most favorable or lucrative environment. Looking to the future, EO is an excellent strategic orientation to enable short-term resource arbitrage opportunities, and to help position the firm for longerterm growth. Thus, our study suggests a more nuanced perspective on the relative role of EO and $\mathrm{MO}$ as strategic orientations employed during an economic crisis by revealing that these strategic orientations have differential utility within our sample of Russian SMEs during crisis.

In contrast to existing studies highlighting the complementary effects of $\mathrm{EO}$ and $\mathrm{MO}$ on firm performance within the context of stable economic conditions (e.g., Atuahene-Gima and Ko 
2001; Boso et al. 2012; 2013a), the results of our analysis suggest a surprising substitutive interaction between $\mathrm{EO}$ and $\mathrm{MO}$ during times of economic downturn and crisis. Resource substitutability is generally discussed in the literature on complementarities as a rationale for competing as opposed to complementary relationships (Ennen and Richter 2010; Voss et al. 2010). While complementarity refers to a beneficial interplay of the factors where the presence of one factor increases the value of another, substitutability manifests when the presence of one factor, contrarily, diminishes the effect of another. Although less prevalent in the literature, substitutive relationships have been documented between such resources as human and financial capital in emerging business ventures (Chandler and Hanks 1998; Xiao and Ramsden 2016), as well as relatively similar factors such as organization's expertise in similar fields (e.g., proximal and distal technological experience) (Nerkar and Roberts 2004), and cooperation between inventors with similar skill sets (Bonaccorsi and Thoma 2007). Moreover, it is difficult to argue for factors whose relationship would always be complementary, which signifies the critical role of contextuality when investigating resource combinations (Ennen and Richter 2010).

Regarding strategic orientations, our findings align with evidence that the simultaneous adoption of high levels of EO and MO may not always lead to an improvement of business performance (Bhuian et al. 2005; Morgan et al. 2015). Our results reveal that to maximize returns from their EO firms appear to be best served when, at least temporarily, deemphasizing their MO during economic crises. Being consistent with the observations of Morgan et al. (2015), the orientations' underlying philosophies may be conflicting in certain circumstances, and their integration is undoubtedly context dependent (Zahra 2008). MO involves a rigorous market analysis and learning about the external environment and its nuances across customers and competitors. According to Grewal and Tansuhaj (2001), this learning might not be applicable during times of crisis since each crisis is unique and firms do not encounter them frequently. Therefore, the potential value of what is learned during crisis times is questionable. Thus, it is possible that MO may either not accurately capture the rare circumstances that firms 
face during a crisis or this information may be less relevant because consumer demands are likely temporary and far less profitable during recession. Such information collected from the external environment may also compete with the internal entrepreneurial culture of the firm, and so negatively impact performance (Morgan et al. 2015). Besides this, high levels of MO may create inertia instead of fostering the creative thinking (Grewal and Tansuhaj 2001). Having a strong customer focus and being competitor oriented has the potential to impede the development of breakthrough ideas and lead to imitation strategies and incremental innovations (Morgan et al. 2015). Thus, accounting for MO when considering the effects of $\mathrm{EO}$ on performance during economic crises provides much needed insight to inform this relationship.

Further, the effects of EO and MO did not appear to be positively moderated by the availability of financial capital during economic crisis. By itself, liquidity and adequate financing opportunities are crucial to firm performance during economic downturn (Latham and Braun 2009), a point supported by its positive direct effect on performance within our sample. However, when operating during economic crisis under circumstances of decline, firms might constrain their strategic options and devote resources to less risky activities rather than resourceintensive strategic behaviors such as EO and MO, thus, explicating the unrevealed moderating role of financial capital. To speculate, this is in line with a threat rigidity perspective which posits that increasingly threatening environmental situations cause firms to retrench from their risk-taking and innovative behaviors and emphasize efficiency and conservation of resources (Staw et al. 1981). Illustrating this, a recent report on economic crisis in Russia indicates that most companies responded to the crisis by introducing a range of optimization measures in production and logistics within extant organizational configurations, but generally avoiding making fundamental changes (Russia's current economic downturn 2015).

Finally, the results of our three-way interaction analysis indicate that the trade-off between $\mathrm{EO}$ and $\mathrm{MO}$ is not lessened in the presence of greater financial resource availability. Study findings suggest that during a period of economic crisis, increases in MO, regardless of the 
extent of financial capital resources available to whether the crisis, are never observed to reinforce the positive effects of EO, but rather still work to diminish it. Thus, firms manifesting high EO along with low MO appear to best weather economic crises compared to firms which seek to simultaneously co-develop both strategic orientations. Thus, while financial capital availability improves performance during economic crisis, it does so most strongly when EO as opposed to MO is the firm's dominant strategic orientation.

The practical implications of these findings are that unlike periods of economic stability when emphasizing both EO and MO may lead to the best outcomes, during periods of economic crisis, organizational managers should focus attention and devote resources to the development of the entrepreneurial elements of their strategy. This can be achieved by focusing on innovative behaviors, a willingness to take risks when marketing new products or services as well as being proactive when considering new opportunities (Covin and Slevin 1989; Soininen et al. 2012). Managers need to be concerned with the effect of attempting to implement both EO and MO simultaneously during crises and recognize that while strategic orientations may be complementary in some contexts, they are competing in others. Our findings point to one such context in which it is best that managers follow a narrower strategic approach rather than attempting to balance multiple strategic orientations, a prescription which holds irrespective of financial resources availability.

\section{Limitations and future research}

As with all research, this study has a number of limitations that should be acknowledged. First, while this study is among the first nationally random and comprehensive samples of Russian SMEs, practical research and resource considerations limited the collection of study variables to one time period. A longitudinal, as opposed to a cross-sectional, design would certainly provide an opportunity to better assess causality. Moreover, it is possible that these effects may change based on how progressed the economic crisis is such as when it is beginning, in full effect, and the worst is over. This is a question for future research. At what point has an economy stabilized 
to a point that $\mathrm{MO}$ is again valuable? Future research may also investigate longer-term consequences of $\mathrm{EO}$ and $\mathrm{MO}$ to confirm propositions that $\mathrm{EO}$ enables firms to better capitalize on long-term gains. Second, while common within research on strategic orientations, most study variables were measured through self-reported assessments by single key informants. While statistical tests were undertaken to help alleviate this concern, replication studies are encouraged using multiple respondents per organization or alternative objective measures of the variables.

This study investigated the role of entrepreneurial and market orientations in capitalizing on economic crisis. Further research may consider adopting a more complex view of firms' strategic behaviour by including other types of strategic behaviour such as learning orientation, absorptive capacity, or ambidexterity to better understand how EO and MO firms process information during times of economic instability and crisis. To date, an information processing perspective has been largely absent the EO literature. Besides this, future studies might test the research model in the contexts of other countries and economic crises to examine its generalizability. The comparison of these results with findings in other settings could provide additional insights to further enhance our understanding of the contextual determinants on key strategic orientation-performance relationships.

In this vein, might there also be presently unaccounted for moderators that enhance the value of MO during economic crisis and strengthen its effect? While we presumed that financial capital availability may serve this role, it does not appear to represent such a factor. Perhaps examining aspects of organizational learning or the severity or cause of the economic crisis in future research may help shed further light on the question of key boundary conditions to observed relationships. To speculate, perhaps aspects of the firm's decision-making processes such as exhibiting a promotion or prevention focus may also shape the value of EO and MO, and their interaction during times of economic downturn. Nonetheless, our results are instructive in that financial capital availability, or lessened resource constraint, does not appear to provide the answer. Along these lines, many questions remain for future research investigations. 


\section{Conclusion}

This study investigates the role of entrepreneurial and market orientations, as well as their integration, in helping firms capitalize on opportunities during an economic crisis. Using a robust sample of Russian SMEs, and accounting for financial capital availability during a recently introduced period of economic crisis, we provide evidence that emphasizing entrepreneurial orientation is most beneficial during economic downturn. Moreover, we observe an adverse unintended consequence of co-developing both entrepreneurial and market orientations during times of economic crisis within our robust national sample of Russian SMEs.

\section{References}

Acharya, V. V., Shin, H. S., \& Yorulmazer, T. (2013). A theory of arbitrage capital. Review of Corporate Finance Studies, 2, 62-97.

Aiken, L. S., \& West, S. G. (1991). Multiple regression: Testing and interpreting interactions. Newbury Park, Calif.: Sage.

Aldrich, H. E., \& Auster, E. (1986). Even dwarfs started small: Liabilities of age and size and their strategic implications. In B. M. Staw \& L. L. Cummings (Eds.), Research in organizational behavior, Vol. VIII: 165-198. Greenwich, CT: JAI Press.

Alonso-Almeida, M. M., Bremser, K., \& Llach, J. (2015). Proactive and reactive strategies deployed by restaurants in times of crisis. International Journal of Contemporary Hospitality Management, 27(7), 1641-1661.

Atuahene-Gima, K., \& Ko, A. (2001). An empirical investigation of the effect of market orientation and entrepreneurship orientation alignment on product innovation. Organization Science, 12(1), 54-74.

Bai, C-E., Lu, J., \& Tao, Z. (2006). Property rights protection and access to bank loans: Evidence from private enterprises in China. Economics of Transition, 14(4), 611-628. 
Baker, W. E., \& Sinkula, J. M. (2009). The complementary effects of market orientation and entrepreneurial orientation on profitability in small businesses. Journal of Small Business Management, 47(4), 443-464.

Bao, Y., Olson, B., \& Yuan, W. (2011). Defensive and expansion responses to environmental shocks in China: Interpreting the 2008 economic crisis. Thunderbird International Business Review, 53(2), 225-245.

Barney, J. (1991). Firm resources and sustained competitive advantage. Journal of Management, 17(1), 99-120.

Bhuian, S. N., Menguc, B., \& Bell, S. J. (2005). Just entrepreneurial enough: The moderating effect of entrepreneurship on the relationship between market orientation and performance. Journal of Business Research, 58(1), 9-17.

Bonaccorsi, A., \& Thoma, G. (2007). Institutional complementarity and inventive performance in nano science and technology. Research Policy, 36(6), 813-831.

Boso, N., Cadogan, J. W., \& Story, V. M. (2012). Complementary effect of entrepreneurial and market orientations on export new product success under differing levels of competitive intensity and financial capital. International Business Review, 21(4), 667-681.

Boso, N., Cadogan, J. W., \& Story, V. M. (2013a). Entrepreneurial orientation and market orientation as drivers of product innovation success: A study of exporters from a developing economy. International Small Business Journal, 31(1), 57-81.

Boso, N., Story, V. M., \& Cadogan, J. W. (2013b). Entrepreneurial orientation, market orientation, network ties, and performance: Study of entrepreneurial firms in a developing economy. Journal of Business Venturing, 28(6), 708-727.

Bradley, S. W., Shepherd, D. A., \& Wiklund, J. (2011). The importance of slack for new organizations facing 'tough' environments. Journal of Management Studies, 48(5), 10711097. 
Brouthers, K. D., Nakos, G., \& Dimitratos, P. (2015). SME entrepreneurial orientation, international performance, and the moderating role of strategic alliances. Entrepreneurship Theory and Practice, 39(5), 1161-1187.

Cambra-Fierro, J., Hart, S., Polo-Redondo, Y., \& Fuster-Mur, A. (2012). Market and learning orientation in times of turbulence: Relevance questioned? An analysis using a multi-case study. Quality \& Quantity, 46(3), 855-871.

Cano, C. R., Carrillat, F. A., \& Jaramillo, F. (2004). A meta-analysis of the relationship between market orientation and business performance: Evidence from five continents. Intern. J. of Research in Marketing, 21(2), 179-200.

Chamber of Commerce and Industry of the Russian Federation (n.d.). www.tpprf.ru/common/upload/documents/activities/podpred/a3.zip. Accessed 2 February 2016.

Chandler, G. N., \& Hanks, S. H. (1998). An examination of the substitutability of founders human and financial capital in emerging business ventures. Journal of business venturing, 13(5), 353-369.

Chang, S.-J., vanWitteloostuijn, A., \& Eden, L. (2010). From the editors: Common method variance in international business research. Journal of International Business Studies, 41(2), $178-184$.

Chattopadhyay, P., Glick, W., \& Huber, G. (2001). Organizational actions in response to threats and opportunities. Academy of Management Journal, 44(5), 937-955.

Cooper, A. C., Gimeno-Gascon, F. J., \& Woo, C. Y. (1994). Initial human and financial capital as predictors of new venture performance. Journal of Business Venturing, 9(5), 371-395.

Cote, J. A., \& Buckley, M. R. (1987). Estimating trait, method, and error variance: generalizing across 70 construct validation studies. Journal of Marketing Research, 24(3), 315-318.

Covin, J. G., \& Slevin, D. P. (1989). Strategic management of small firms in hostile and benign environments. Strategic Management Journal, 10(1), 75-87. 
Covin, J. G., \& Slevin, D. P. (1991). A conceptual model of entrepreneurship as firm's behavior. Entrepreneurship Theory and Practice, 16(1), 7-25.

Dawson, J. F., \& Richter, A. W. (2006). Probing three-way interactions in moderated multiple regression: Development and application of a slope difference test. Journal of Applied Psychology, 91(4), 917-926.

Deutscher, F., Zapkau, F. B., Schwens, C., Baum, M., \& Kabst, R. (2016). Strategic orientations and performance: A configurational perspective. Journal of Business Research, 69(2), 849861.

Ellis, P. D. (2006). Market orientation and performance: A meta-analysis and cross-national comparisons. Journal of Management Studies, 43(5), 1089-1107.

Ennen, E., \& Richter, A. (2010). The whole is more than the sum of its parts- or is it? A review of the empirical literature on complementarities in organizations. Journal of Management, $36(1), 207-233$.

$\begin{array}{lllll}\text { Federal } & \text { State } & \text { Statistics } & \text { Service. } & 2017 .\end{array}$ http://www.gks.ru/wps/wcm/connect/rosstat_main/rosstat/ru/. Accessed 5 September 2017.

Fornell, C., \& Larcker, D. (1981). Evaluating structural equation models with unobservable variables and measurement error. Journal of Marketing Research, 18(1), 39-50.

Gatignon, H., \& Xuereb, M. (1997). Strategic orientation of the firm and new product performance. Journal of Marketing Research, 34(1), 77-90.

Gerbing, D., \& Anderson, J. (1988). An updated paradigm for scale development incorporating unidimensionality and its assessment. Journal of Marketing Research, 25(2), 186-192.

González-Benito, Ó., González-Benito, J., \& Muñoz-Gallego, P. A. (2009). Role of entrepreneurship and market orientation in firms' success. European Journal of Marketing, $43(3 / 4), 500-522$. 
Grewal, R., \& Tansuhaj, P. (2001). Building organizational capabilities for managing economic crisis: The role of market orientation and strategic flexibility. Journal of Marketing, 65(2), $67-80$.

Hakala, H. (2011). Strategic orientations in management literature: Three approaches to understanding the interaction between market, technology, entrepreneurial and learning orientations. International Journal of Management Reviews, 13(2), 199-217.

Hambrick, D. C. (2003). On the staying power of defenders, analyzers, and prospectors. Academy of Management Executive, 17(4), 115-118.

Ho, J., Plewa, C., \& Lu, V. N. (2016). Examining strategic orientation complementarity using multiple regression analysis and fuzzy set QCA. Journal of Business Research, 69(6), 21992205.

Huhtala, J. P., Sihvonen, A., Frösén, J., Jaakkola, M., \& Tikkanen, H. (2014). Market orientation, innovation capability and business performance: Insights from the global financial crisis. Baltic Journal of Management, 9(2), 134-152.

Hult, G. T. M., Hurley, R. F., \& Knight, G. A. (2004). Innovativeness: Its antecedents and impact on business performance. Industrial Marketing Management, 33(5), 429-438.

Kale, S., \& Arditi, D. (1998). Business failures: Liability of newness, adolescence, smallness. Journal of Construction Engineering and Management, 124(6), 458-467.

Kaleka, A. (2002). Resources and capabilities driving competitive advantage in export markets: Guidelines for industrial exporters. Industrial Marketing Management, 31(3), 273-283.

Kohli, A. K., \& Jaworski, B. J. (1990). Market orientation: The construct, research propositions, and managerial implications. Journal of Marketing, 54(2), 1-18.

Kumar, V., Jones, E., Venkatesan, R., \& Leone, R. P. (2011). Is market orientation a source of sustainable competitive advantage or simply the cost of competing? Journal of Marketing, 75(1), 16-30. 
Kunc, M., \& Bhandari, R. (2011). Strategic development processes during economic and financial crisis. Management Decision, 49(8), 1343-1353.

Latham, S. F. (2005). Examining creative destruction in the IT industry: A resource-based view perspective. Ph.D. dissertation, University of Massachusetts Amherst.

Latham, S., \& Braun, M. R. (2009). Assessing the relationship between financial slack and company performance during an economic recession: An empirical study. International Journal of Management, 26(1), 33-39.

Laukkanen, T., Nagy, G., Hirvonen, S., Reijonen, H., \& Pasanen, M. (2013). The effect of strategic orientations on business performance in SMEs: A multigroup analysis comparing Hungary and Finland. International Marketing Review, 30(6), 510-535.

Lettice, F., Tschida, M., \& Forstenlechner, I. (2014). Managing in an economic crisis: The role of market orientation in an international law firm. Journal of Business Research, 67(1), 2693-2700.

Li, Y., Wei, Z., \& Liu, Y. (2010). Strategic orientations, knowledge acquisition, and firm performance: The perspective of the vendor in cross-border outsourcing. Journal of Management Studies, 47(8), 1457-1482.

Ling Y., \& Kellermanns, F. W. (2010). The effects of family firm specific sources of TMT diversity: The moderating role of information exchange frequency. Journal of Management Studies, 47(2), 322-344.

Liu, Y., Li, Y., \& Xue, J. (2011). Ownership, strategic orientation and internationalization in emerging markets. Journal of World Business, 46(3), 381-393.

Lonial, S. C., \& Carter, R. E. (2015). The impact of organizational orientations on medium and small firm performance: A resource-based perspective. Journal of Small Business Management, 53(1), 94-113.

Lumpkin, G. T., \& Dess, G. G. (1996). Clarifying the entrepreneurial orientation construct and linking it to performance. Academy of Management Review, 21(1), 135-172. 
Lumpkin, G. T., \& Dess, G. G. (2001). Linking two dimensions of entrepreneurial orientation to firm performance: The moderating role of environment and industry life cycle. Journal of Business Venturing, 16(5), 429-451.

Marino, L. D., Lohrke, F. T., Hill, J. S., Weaver, K. M., \&Tambunan, T. (2008). Environmental shocks and SME alliance formation intentions in an emerging economy: Evidence from the Asian financial crisis in Indonesia. Entrepreneurship: Theory and Practice, 32(1), 157-183.

Mau, V., \& Ulyukaev, A. (2015). Global crisis and challenges for Russian economic development. Russian Journal of Economics, 1(1), 4-29.

Meyer, K. E. (2015). Context in management research in emerging economies. Management and Organization Review, 11(3), 369-377.

Milgrom, P., \& Roberts, J. (1995). Complementarities and fit. Strategy, structure, and organizational change in manufacturing. Journal of Accounting and Economics, 19(2-3), 179-208.

Miller, D. (2011). Miller (1983) revisited: A reflection on EO research and some suggestions for the future. Entrepreneurship Theory and Practice, 35(5), 873-894.

Morgan T., Anokhin, S., Kretinin, A., \& Frishammar, J. (2015). The dark side of the entrepreneurial orientation and market orientation interplay: A new product development perspective. International Small Business Journal, 33(7), 731-751.

Morgan, R. E., \& Berthon, P. (2008). Market orientation, generative learning, innovation strategy and business performance inter-relationships in bioscience firms. Journal of Management Studies, 45(8), 1329-1353.

Naidoo, V. (2010). Firm survival through a crisis: The influence of market orientation, marketing innovation and business strategy. Industrial Marketing Management, 39(8), 1311-1320.

Narver, J., \& Slater, S. (1990). The effect of a market orientation on business profitability. Journal of Marketing, 54(4), 20-35. 
Nerkar, A., \& Roberts, P. W. (2004). Technological and product-market experience and the success of new product introductions in the pharmaceutical industry. Strategic Management Journal, 25(8-9), 779-799.

Nunnally, J. C. (1978). Psychometric theory. New York: McGraw-Hill.

Özturan, P., Özsomer, A., \& Pieters, R. (2014). The role of market orientation in advertising spending during economic collapse: The case of Turkey in 2001. Journal of Marketing Research, 51(2), 139-152.

Pearce II, J. A., \& Michael, S. C. (2006). Strategies to prevent economic recessions from causing business failure. Business Horizons, 49(3), 201-209.

Pearson, C., \& Clair, J. (1998). Reframing crisis management. Academy of Management Review, 23(1), 59-76.

Podsakoff, P. M., \& Organ, D. W. (1986). Self-Reports in organizational research: Problems and prospects. Journal of Management, 12(4), 531-544.

Pollard, D., \& Hotho, S. (2006). Crises, scenarios and the strategic management process. Management Decision, 44(6), 721-736.

Rauch, A., Wiklund, J., Lumpkin, G. T., \& Frese, M. (2009). Entrepreneurial orientation and business performance: An assessment of past research and suggestions for the future. Entrepreneurship Theory and Practice, 33(3), 761-787.

Rosenbusch, N., Rauch, A., \& Bausch, A. (2013). The mediating role of entrepreneurial orientation in the task environment-performance relationship: A meta-analysis. Journal of Management, 39(3), 633-659.

Russia's current economic downturn: a $360^{\circ}$ view. PwC. 2015. https://www.pwc.ru/en/publications/assets/e-crisis-survey_eng.pdf. Accessed 11 December 2017.

Skrondal, A., \& Laake P. (2001). Regression among factor scores. Psychometrika, 66(4), 563575. 
Shirokova, G., Vega, G., \& Sokolova, L. (2013). Performance of Russian SMEs: exploration, exploitation and strategic entrepreneurship. Critical Perspectives on International Business, 9(1/2), 173-203.

Slater, S. F., \& Narver, J. C. (2000). The positive effect of a market orientation on business profitability: A balanced replication. Journal of Business Research, 48, 69-73.

SME Bank. 2015. Quality Index of Conditions for Small and Medium Business in 2013-2014. Regional Disproportions. https://www.mspbank.ru/userfiles/files/researches/index_kach_2013-2014.pdf. Accessed 5 February 2016.

Soininen, J., Puumalainen, K., Sjögrén, H., \& Syrjä, P. (2012). The impact of global economic crisis on SMEs. Does entrepreneurial orientation matter? Management Research Review, 35(10), 927-944.

Song, L., \& Jing, L. (2017). Strategic orientation and performance of new ventures: Empirical studies based on entrepreneurial activities in China. International Entrepreneurship and Management Journal, 1-24.

Staw, B. M., Sandelands, L. E., \& Dutton, J. E. (1981). Threat-rigidity effects in organizational behavior: A multilevel analysis. Administrative Science Quarterly, 26(4): 501-524.

Story, V. M., Boso, N., \& Cadogan, J. W. (2015). The form of relationship between firm-level product innovativeness and new product performance in developed and emerging markets. Journal of Product Innovation Management, 32(1), 45-64.

Strotmann, H. (2007). Entrepreneurial survival. Small Business Economics, 28(1), 87-104.

Tan, H., \& See, H. (2004). Strategic reorientation and responses to the Asian financial crisis: The case of the manufacturing industry in Singapore. Asia Pacific Journal of Management, 21(1), 189-211.

Tangpong, C., Abebe, M., \& Li, Z. (2015). A temporal approach to retrenchment and successful turnaround in declining firms. Journal of Management Studies, 52(5), 647-677. 
Vaaler, P. M., \& McNamara, G. (2004). Crisis and competition in expert organisational decision making: Credit-rating agencies and their response to turbulence in emerging economies. Organisation Design, 15(6), 687-703.

Venkatraman, N. (1989). Strategic orientation of business enterprises: The construct, dimensionality, and measurement. Management Science, 35(8), 942-962.

Voss, G. B., Godfrey, A., \& Seiders, K. (2010). How complementarity and substitution alter the customer satisfaction-repurchase link. Journal of Marketing, 74(6), 111-127.

Voss, G. B., Sirdeshmukh, D., \& Voss, Z. G. (2008). The effects of slack resources and environmental threat on product exploration and exploitation. Academy of Management Journal, 51(1), 147-164.

Wales, W. J., Gupta, V. K., \& Mousa, F. T. (2013). Empirical research on entrepreneurial orientation: An assessment and suggestions for future research. International Small Business Journal, 31(4), 357-383.

Wijesekara, W. A. D. S., Samantha Kumara, P. A. P., \& Gunawardana, T. S. L. W. (2016). Relationships between market and entrepreneurial orientation and organizational performance: Empirical evidence from small and medium scale garment manufacturers in Sri Lanka. Journal of Enterprising Culture, 24(1), 37-53.

Wiklund, J., \& Shepherd, D. (2005). Entrepreneurial orientation and small business performance: A configurational approach. Journal of Business Venturing, 20(1), 71-89.

Wiklund, J., \& Shepherd, D. (2011). Where to from here? EO-as-experementation, failure, and distribution of outcomes. Entrepreneurship Theory and Practice, 35(5), 925-946.

Xiao, L., \& Ramsden, M. (2016), Founder expertise, strategic choices, formation, and survival of high-tech SMEs in China: A resource-substitution approach. Journal of Small Business Management, 54(3), 892-911.

Zahra, S. A. (2008). Being entrepreneurial and market-driven: Implications for company performance. Journal of Strategy and Management, 1(2), 125-142. 
Zahra, S. A., \& Covin, J. G. (1995). Contextual influences on the corporate entrepreneurshipperformance relationship: A longitudinal analysis. Journal of Business Venturing, 10(1), 4358.

Zortea-Johnston, E., Darroch, J., \& Matear, S. (2012). Business orientations and innovation in small and medium sized enterprises. International Entrepreneurship and Management Journal, 8(2), 145-164. 
Table 1 Summary of studies on strategic orientations in economic crisis context

\begin{tabular}{|c|c|c|}
\hline Author & Study context & Key findings \\
\hline \multicolumn{3}{|c|}{ Prior studies investigating EO in economic crisis } \\
\hline Marino et al. (2008) & $\begin{array}{l}\text { Asian financial crisis } \\
\text { 1997-1998, Indonesia, } \\
271 \text { SMEs }\end{array}$ & $\begin{array}{l}\text { Firm with high EO are more inclined to form strategic } \\
\text { alliances in the temporary shock environment }\end{array}$ \\
\hline $\begin{array}{l}\text { Soininen et al. } \\
\text { (2012) }\end{array}$ & $\begin{array}{l}\text { Global economic crisis } \\
\text { 2008, Finland, } \\
194 \text { SMEs }\end{array}$ & $\begin{array}{l}\text { The more innovative and proactive the firm is, the less } \\
\text { its operations are affected by the recession, compared } \\
\text { to risk-taking firms }\end{array}$ \\
\hline \multicolumn{3}{|c|}{ Prior studies investigating $\mathrm{MO}$ in economic crisis } \\
\hline $\begin{array}{l}\text { Grewal and } \\
\text { Tansuhaj (2001) }\end{array}$ & $\begin{array}{l}\text { Asian financial crisis } \\
\text { 1997-1998, Thailand, } \\
\text { 120 SMEs }\end{array}$ & $\begin{array}{l}\text { Market orientation has an adverse effect on firm } \\
\text { performance after a crisis and is complemented by } \\
\text { strategic flexibility to help firms manage varying } \\
\text { environmental conditions. }\end{array}$ \\
\hline Naidoo (2010) & $\begin{array}{l}\text { Global economic crisis } \\
\text { 2008, China, } \\
184 \text { SMEs }\end{array}$ & $\begin{array}{l}\text { Competitor orientation and inter-functional } \\
\text { coordination are positively related to marketing } \\
\text { innovation capabilities which assist in developing } \\
\text { competitive advantages and enhancing a likelihood of } \\
\text { survival. }\end{array}$ \\
\hline $\begin{array}{l}\text { Cambra-Fierro et al. } \\
(2012)\end{array}$ & $\begin{array}{l}\text { Global economic crisis } \\
2008, \text { Spain, } \\
12 \text { case firms }\end{array}$ & $\begin{array}{l}\text { Market and learning-orientated firms exhibit proactive } \\
\text { behavior patterns and are better prepared for the period } \\
\text { of crisis and turbulence. }\end{array}$ \\
\hline Huhtala et al. (2014) & $\begin{array}{l}\text { Global economic crisis } \\
\text { 2008, Finland, } \\
258 \text { firms }\end{array}$ & $\begin{array}{l}\text { The general performance impact of MO increases } \\
\text { during an economic downturn. The role of customer } \\
\text { orientation is emphasized during an upturn, whereas } \\
\text { competitor orientation and inter-functional } \\
\text { coordination are more important during a downturn. }\end{array}$ \\
\hline Lettice et al. (2014) & $\begin{array}{l}\text { Global economic crisis } \\
\text { 2008, case of a } \\
\text { multinational firm }\end{array}$ & $\begin{array}{l}\text { Practice groups with higher MO scores withstand the } \\
\text { increased turbulence and outperform those practice } \\
\text { groups with lower MO scores. }\end{array}$ \\
\hline Özturan et al. (2014) & $\begin{array}{l}\text { Economic crisis in } \\
\text { Turkey 2001, } \\
403 \text { firms }\end{array}$ & $\begin{array}{l}\text { During the economic contraction, the responsiveness } \\
\text { MO facet is positively while intelligence facet is } \\
\text { negatively associated with increases in advertising } \\
\text { spending, which predict better subsequent business } \\
\text { performance. }\end{array}$ \\
\hline
\end{tabular}


Table 2 Industries and federal districts participating in this study

\begin{tabular}{lcc}
\hline Categories & Frequency & Percent \\
\hline Industry & & \\
Exploration and mining of minerals & 11 & 1.80 \\
Construction & 71 & 11.60 \\
Manufacturing & 103 & 16.83 \\
Transportation and logistics, communications, & & \\
electricity, gas and sanitary services & 32 & 5.23 \\
Wholesale trade & 134 & 21.90 \\
Retail trade & 107 & 17.48 \\
Services & 133 & 21.73 \\
Other & 21 & 3.43 \\
Federal district & & \\
Central & 170 & 27.78 \\
Southern & 34 & 5.56 \\
Northwestern & 73 & 11.93 \\
Far Eastern & 24 & 3.92 \\
Siberian & 113 & 18.46 \\
Ural & 72 & 11.76 \\
Volga & 118 & 19.28 \\
North Caucasian & 8 & 1.31 \\
Total & 612 & 100 \\
\hline
\end{tabular}


Table 3 Constructs, measurement items and reliability and validity tests

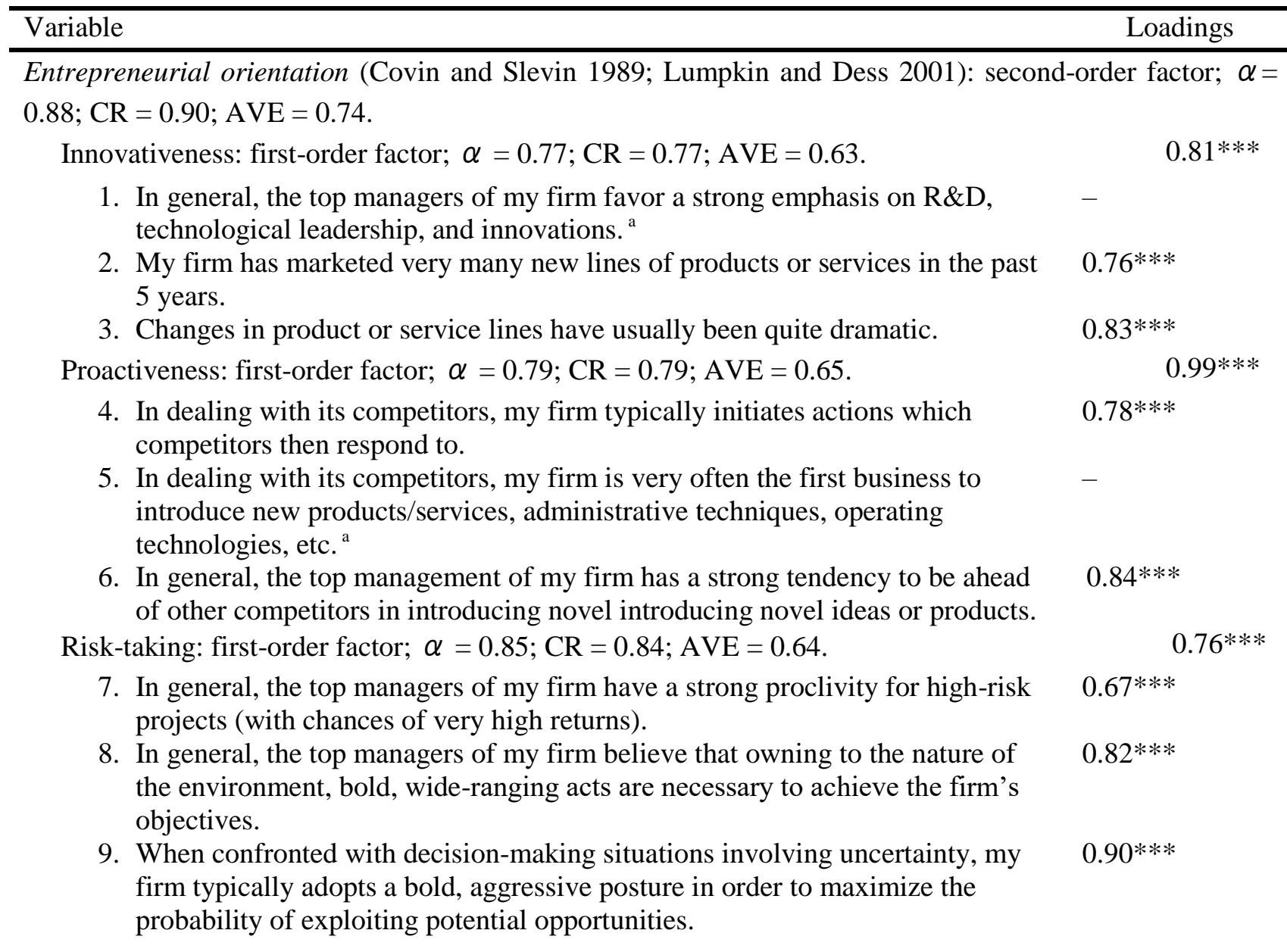

Market orientation (Narver and Slater 1990): second-order factor; $\alpha=0.87 ; \mathrm{CR}=0.84 ; \mathrm{AVE}=0.63$.

Customer orientation: first-order factor; $\alpha=0.86 ; \mathrm{CR}=0.83$; $\mathrm{AVE}=0.50$.

1. We constantly monitor our level of commitment and orientation to serving customers' needs.

2. Our business strategies are driven by our beliefs about how we can create

$0.71 * * *$ greater value for customers.

3. Our strategy for competitive advantage is based on our understanding of customer needs.

4. Our business objectives are driven primarily by customer satisfaction.

$0.75 * * *$

5. We give close attention to after-sales service.

$0.71 * * *$

6. We measure customer satisfaction systematically and frequently. ${ }^{\mathrm{a}}$

Competitor orientation: first-order factor; $\alpha=0.69 ; \mathrm{CR}=0.69$; $\mathrm{AVE}=0.52$.

7. The top management team regularly discusses competitors' strengths and strategies.

8. We target customers and customer groups where we have, or can develop, a competitive advantage.

9. Our salespeople regularly share information within our business concerning competitors' strategies. $^{\text {a }}$

10. We rapidly respond to competitive actions that threaten us. ${ }^{\text {a }}$ 
Inter-functional coordination: first-order factor; $\alpha=0.84 ; \mathrm{CR}=0.80 ; \mathrm{AVE}=0.50$.

11. Our top managers from every function regularly visit our current and prospective customers. $^{\text {a }}$

12. We freely communicate information about our successful and unsuccessful customer experiences across all business functions.

13. All of our business functions (e.g. marketing/sales, manufacturing, $R \& D$, finance/accounting, etc.) are integrated in serving the needs of our target markets.

14. All of our managers understand how everyone in our company can contribute to creating customer value.

15. All of our business functions share resources with other business units (information, etc.).

Financial capital availability (Story et al. 2015): $\alpha=0.91 ; \mathrm{CR}=0.91 ; \mathrm{AVE}=0.71$.

1. Our company has easy access to financial capital to support its business operations

2. If we need more financial assistance for our business operations, we could easily get it

3. We have substantial financial resources at the discretion of managers for funding business initiatives

4. We are able to obtain financial resources at short notice to support business operations

Performance impact of economic crisis (Latham 2005): $\alpha=0.91 ; \mathrm{CR}=0.92 ; \mathrm{AVE}=0.73$.

1. Sales Revenue

2. Profitability

3. Pricing

4. Average Deal Size

Notes: $\alpha=$ Cronbach alpha; $\mathrm{CR}=$ composite reliability; $\mathrm{AVE}=$ average variance extracted.

$* * * \mathrm{p}<0.001$.

${ }^{a}$ the item was omitted as a result of CFA. 
Table 4 Descriptive statistics and correlations

\begin{tabular}{|c|c|c|c|c|c|c|c|c|c|c|c|c|c|c|c|c|c|c|c|}
\hline $\mathrm{N}$ & Variable & Mean & S.D. & 1 & 2 & 3 & 4 & 5 & 6 & 7 & 8 & 9 & 10 & 11 & 12 & 13 & 14 & 15 & 16 \\
\hline 1 & $\begin{array}{l}\text { Performance } \\
\text { impact of } \\
\text { economic crisis }\end{array}$ & 3.14 & 1.22 & & & & & & & & & & & & & & & & \\
\hline 2 & Firm age $^{\mathrm{a}}$ & 2.32 & 0.71 & -0.06 & & & & & & & & & & & & & & & \\
\hline 3 & Firm size $^{\mathrm{a}}$ & 2.95 & 1.19 & $0.10 *$ & $0.34 *$ & & & & & & & & & & & & & & \\
\hline 4 & Mining & - & - & -0.02 & 0.02 & 0.07 & & & & & & & & & & & & & \\
\hline 5 & Construction & - & - & 0.00 & $-0.09 *$ & $0.08 *$ & -0.05 & & & & & & & & & & & & \\
\hline 6 & Manufacturing & - & - & 0.02 & $0.18 *$ & $0.24 *$ & -0.06 & $-0.16^{*}$ & & & & & & & & & & & \\
\hline 7 & Transportation & - & - & -0.03 & -0.03 & -0.01 & -0.03 & $-0.09 *$ & $-0.11 *$ & & & & & & & & & & \\
\hline 8 & Wholesale & - & - & 0.01 & $-0.13 *$ & $-0.26^{*}$ & -0.07 & $-0.19 *$ & $-0.24 *$ & $-0.12 *$ & & & & & & & & & \\
\hline 9 & Retail & - & - & 0.01 & 0.03 & $-0.09 *$ & -0.06 & $-0.17 *$ & $-0.21 *$ & $-0.11 *$ & $-0.24 *$ & & & & & & & & \\
\hline 10 & Services & - & - & -0.01 & 0.01 & 0.02 & -0.07 & $-0.19 *$ & $-0.24 *$ & $-0.12 *$ & $-0.28 *$ & $-0.24 *$ & & & & & & & \\
\hline 11 & Others & - & - & -0.02 & 0.04 & 0.06 & -0.03 & -0.07 & $-0.08 *$ & -0.04 & $-0.09 *$ & $-0.09 *$ & $-0.09 *$ & & & & & & \\
\hline 12 & Past performance ${ }^{a}$ & 16.81 & 1.98 & $0.11 *$ & $0.17 *$ & $0.56^{*}$ & 0.04 & -0.00 & $0.13 *$ & -0.06 & 0.08 & -0.04 & $-0.13^{*}$ & -0.01 & & & & & \\
\hline 13 & $\begin{array}{l}\text { Index of regional } \\
\text { development }\end{array}$ & 11.25 & 2.11 & -0.05 & -0.01 & 0.02 & -0.05 & -0.05 & 0.07 & -0.04 & 0.06 & -0.07 & 0.00 & 0.02 & 0.07 & & & & \\
\hline 14 & GRP dynamics & 99.61 & 2.15 & 0.06 & $0.11 *$ & 0.02 & 0.01 & -0.05 & 0.03 & 0.05 & 0.03 & -0.03 & -0.02 & 0.01 & 0.05 & 0.05 & & & \\
\hline 15 & $\begin{array}{l}\text { Entrepreneurial } \\
\text { orientation }\end{array}$ & 3.73 & 1.42 & $0.18^{*}$ & -0.01 & $0.11 *$ & -0.06 & 0.03 & 0.07 & -0.05 & -0.01 & $-0.09 *$ & 0.05 & 0.01 & 0.04 & $0.09 *$ & 0.01 & & \\
\hline 16 & $\begin{array}{l}\text { Market } \\
\text { orientation }\end{array}$ & 5.18 & 1.04 & $0.11 *$ & 0.02 & 0.06 & 0.06 & 0.04 & 0.02 & -0.07 & 0.02 & -0.07 & 0.00 & 0.02 & 0.01 & -0.01 & 0.01 & $0.41 *$ & \\
\hline 17 & $\begin{array}{l}\text { Financial capital } \\
\text { availability }\end{array}$ & 3.16 & 1.26 & $0.20^{*}$ & 0.06 & $0.14 *$ & 0.00 & -0.04 & 0.01 & $0.08 *$ & -0.01 & 0.05 & -0.05 & -0.02 & $0.09 *$ & -0.01 & 0.05 & $0.09 *$ & 0.06 \\
\hline
\end{tabular}

Notes: $\mathrm{n}=612 ; * p<0.05$ (two-tailed).

${ }^{a}$ Natural logarithm taken. 
Table 5 Predicting performance impact of economic crisis: moderated regression analysis

\begin{tabular}{|c|c|c|c|c|}
\hline Variables & Model 1 & Model 2 & Model 3 & Model 4 \\
\hline \multicolumn{5}{|l|}{ Control variables } \\
\hline \multirow[t]{2}{*}{ Firm age } & $-0.21 *$ & $-0.20 *$ & $-0.20 *$ & $-0.20 *$ \\
\hline & $(0.10)$ & $(0.09)$ & $(0.10)$ & $(0.09)$ \\
\hline \multirow[t]{2}{*}{ Firm size } & $0.12 *$ & 0.07 & 0.07 & 0.07 \\
\hline & $(0.06)$ & $(0.04)$ & $(0.05)$ & $(0.05)$ \\
\hline \multirow[t]{2}{*}{ Past performance } & 0.04 & $0.05^{*}$ & $0.05 *$ & $0.05^{*}$ \\
\hline & $(0.02)$ & $(0.02)$ & $(0.02)$ & $(0.02)$ \\
\hline \multirow[t]{2}{*}{ Index of regional development } & -0.04 & -0.04 & -0.04 & -0.04 \\
\hline & $(0.02)$ & $(0.03)$ & $(0.02)$ & $(0.03)$ \\
\hline \multirow[t]{2}{*}{ GRP dynamics } & $0.04^{*}$ & $0.04 *$ & $0.04 *$ & $0.03^{*}$ \\
\hline & $(0.02)$ & $(0.02)$ & $(0.02)$ & $(0.02)$ \\
\hline Industry effects & IN & IN & IN & IN \\
\hline \multicolumn{5}{|l|}{ Main effects } \\
\hline \multirow[t]{2}{*}{ Entrepreneurial orientation (EO) } & & $0.13 * *$ & $0.14 * *$ & $0.14 * *$ \\
\hline & & $(0.05)$ & $(0.05)$ & $(0.05)$ \\
\hline \multirow[t]{2}{*}{ Market orientation (MO) } & & 0.04 & 0.01 & 0.02 \\
\hline & & $(0.05)$ & $(0.06)$ & $(0.06)$ \\
\hline \multirow[t]{2}{*}{ Financial capital availability (FC) } & & $0.17 * * *$ & $0.16^{* *}$ & $0.20 * *$ \\
\hline & & $(0.03)$ & $(0.04)$ & $(0.04)$ \\
\hline \multicolumn{5}{|l|}{ Two-way interactions } \\
\hline \multirow[t]{2}{*}{$\mathrm{EO} \times \mathrm{FC}$} & & & 0.00 & 0.02 \\
\hline & & & $(0.03)$ & $(0.03)$ \\
\hline \multirow[t]{2}{*}{$\mathrm{MO} \times \mathrm{FC}$} & & & 0.01 & -0.01 \\
\hline & & & $(0.06)$ & $(0.06)$ \\
\hline \multirow[t]{2}{*}{$\mathrm{EO} \times \mathrm{MO}$} & & & $-0.11 * *$ & $-0.10^{*}$ \\
\hline & & & $(0.05)$ & $(0.05)$ \\
\hline \multicolumn{5}{|l|}{ Three-way interaction } \\
\hline \multirow[t]{2}{*}{$\mathrm{EO} \times \mathrm{MO} \times \mathrm{FC}$} & & & & $-0.05 * *$ \\
\hline & & & & $(0.01)$ \\
\hline \multirow[t]{2}{*}{ Constant } & -1.03 & -1.59 & -0.31 & -0.16 \\
\hline & $(2.41)$ & $(2.12)$ & $(1.99)$ & $(1.86)$ \\
\hline $\mathrm{R}^{2}$ & 0.04 & 0.10 & 0.11 & 0.12 \\
\hline $\mathrm{R}^{2}$ difference & - & $0.06^{* * *}$ & $0.02 * *$ & $0.01 * *$ \\
\hline
\end{tabular}

Notes: $\mathrm{n}=612$, number of federal districts $=8$; all models are statistically significant. Standard errors are reported in parentheses (heteroskedasticity-robust, clustered at the federal district level).

$* * * p<0.001 ; * * p<0.05, * p<0.10$ 
Table 6 Slope difference test

\begin{tabular}{lcc}
\hline Pair of slopes & t-value for slope difference & p-value for slope difference \\
\hline (1) and (2) & -1.102 & 0.271 \\
(1) and (3) & -3.088 & 0.002 \\
(1) and (4) & -2.375 & 0.018 \\
(2) and (3) & -1.718 & 0.086 \\
(2) and (4) & -1.075 & 0.283 \\
(3) and (4) & 1.690 & 0.092 \\
\hline
\end{tabular}




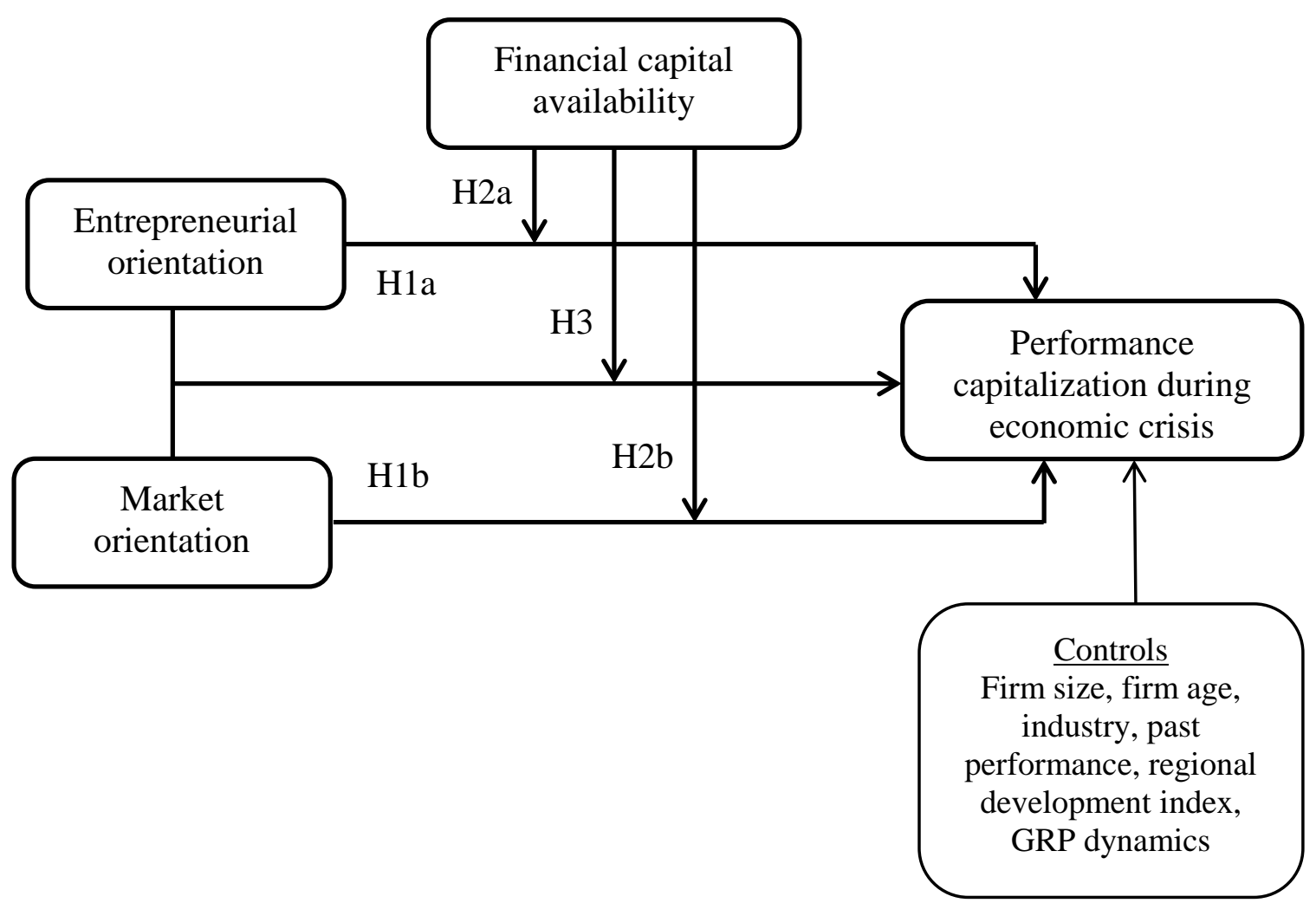

Fig. 1 Research model and hypothesized relationships 


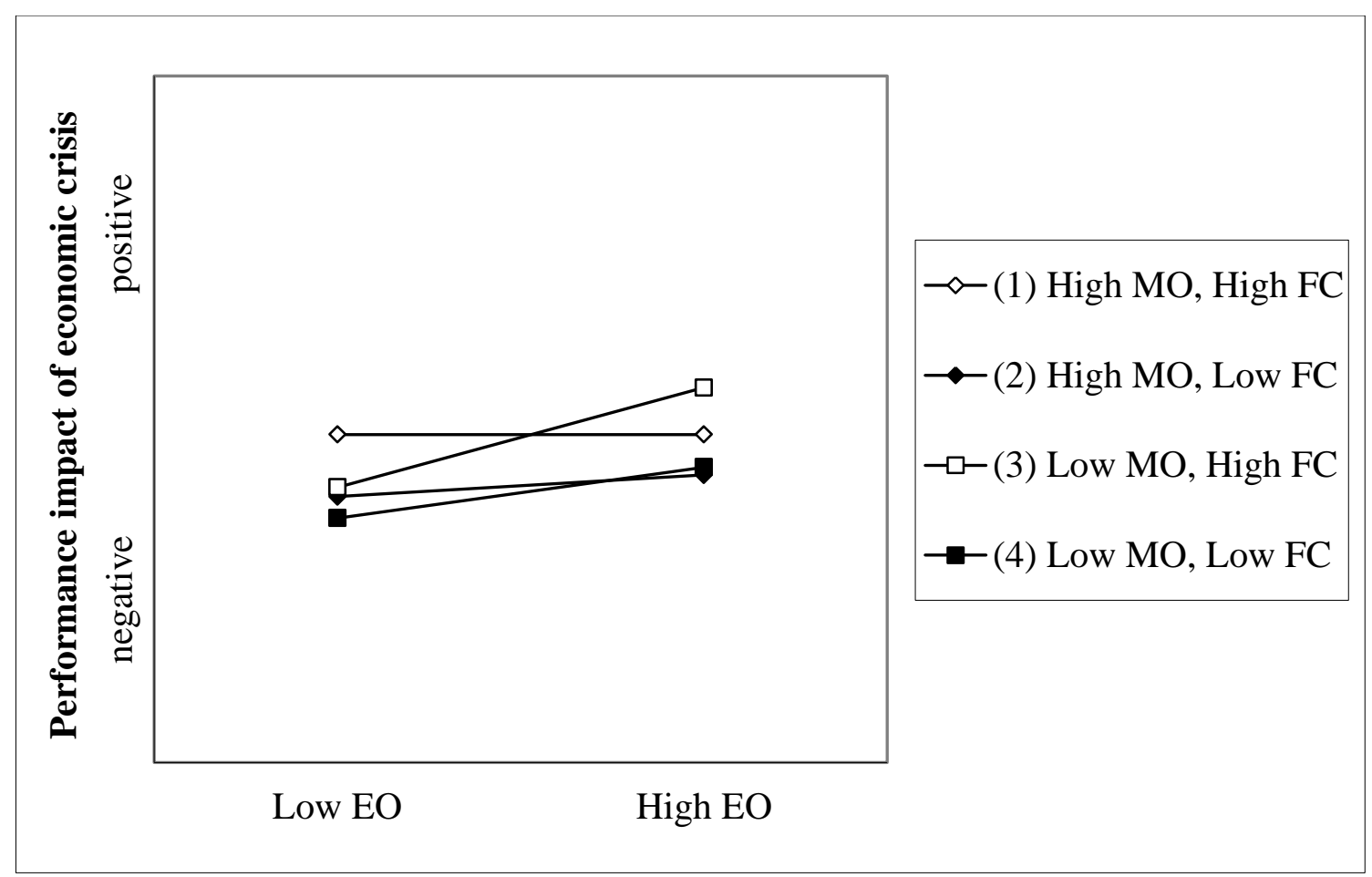

Fig. 2 Plotting interaction effects of entrepreneurial orientation, market orientation, and financial capital availability 